\title{
Post-exercise rehydration with beer impairs fluid retention, reaction time, and balance
}

\author{
Rebeca Flores-Salamanca and Luis Fernando Aragón-Vargas \\ Human Movement Science Research Center, University of Costa Rica \\ rebe08@gmail.com \\ luis.aragon@ucr.ac.cr
}

\begin{abstract}
Beer is promoted by the popular media as a good choice for rehydration, but there is limited support for the claim. To assess the effect of beer alcohol on rehydration and motor control, 11 young ( $24.4 \pm 3.7$ y.o.) males of legal drinking age were dehydrated to $2.12 \pm 0.20 \% \mathrm{BM}$ (mean \pm $\mathrm{SD})$ by exercising in a climatic chamber $\left(31.7 \pm 1.6^{\circ} \mathrm{C}, 55.0 \pm 8.3 \%\right.$ r.h. $)$ on three different days, one week apart, and rehydrated with $100 \%$ of their sweat loss using WATER, $4.6 \%$ alcohol BEER, or nonalcoholic beer (NAB), in random order. Urine output, blood alcohol content (BAC), reaction time (RT), and balance (VCOP) were measured every 30min over three hours and compared via two-way, repeated-measures ANOVAs. After consuming $\approx 1.6 \mathrm{~L}$ in one hour, urine output was greater for BEER $(1218 \pm 279 \mathrm{~mL})$ than NAB $(745 \pm 313, \mathrm{p}=0.007)$ and WATER (774 $\pm 304, p=0.043)$. BAC remained at 0 with WATER and NAB; with BEER, the 95\%CI was $[0.752,0.963 \mathrm{~g} / \mathrm{L}]$ immediately post-rehydration. RT was longer for BEER $(0.314 \pm$ $0.039 \mathrm{~s})$ vs NAB $(0.294 \pm 0.034 \mathrm{~s}, \mathrm{p}=0.009)$, but no different from WATER $(0.293 \pm 0.049 \mathrm{~s}, \mathrm{p}=$ 0.077). VCOPX was significantly higher for BEER $\left(0.0284 \pm 0.0020 \mathrm{~m} * \mathrm{~s}^{-1}\right)$ compared with NAB $\left(0.0233 \pm 0.0010 \mathrm{~m} * \mathrm{~s}^{-1}\right)$ or WATER $\left(0.0238 \pm 0.0010 \mathrm{~m} * \mathrm{~s}^{-1}\right)(\mathrm{p}=0.022)$, but VCOPy was not different among beverages. In conclusion, rehydration with BEER resulted in higher diuresis, slower reaction time, and impaired balance, compared with NAB or WATER.
\end{abstract}

KEYWORDS: Alcohol. Fluid Balance. Dehydration. Diuresis: drug effects. Diuretics. Ethanol. Humans.

Both physically active people and athletes are known to incur significant sweat losses during exercise, particularly in hot and humid environments. Because of practical restrictions, personal choice, or even sports rules, those losses are often not replaced during physical activity, training, or competition, and therefore must be replaced after exercise (Aragón-Vargas et al. 2009). Spontaneous drinking (with meals or without them) may be sufficient to replace lost fluids, but many situations require more aggressive rehydration protocols. In those circumstances, the amount and composition of ingested fluids is crucial to achieve euhydration within a reasonable time and to maintain it afterwards. The presence of electrolytes, particularly sodium, will promote fluid retention and therefore enhance the rehydration process (Jeukendrup et al. 
2009, Shirreffs et al. 1996, Shirreffs and Maughan 1998). In addition, due to obligatory fluid loss via urine, people are typically recommended to replace $150 \%$ of their fluid deficit (Sawka et al. 2007).

Carbohydrate-electrolyte drinks specifically formulated to facilitate hydration have been widely studied for their post-exercise rehydration properties, but other beverages commonly consumed have also been used in experimental research for this purpose. Some of them have been shown to provide higher fluid retention than plain water, including coconut water (Kalman et al. 2012, Ismail, Singh and Sirisinghe 2007, Pérez-Idárraga and Aragón-Vargas 2011, Saat et al. 2002) and milk (Shirreffs, Watson and Maughan 2007), while others such as tea (Wong and Chen 2011), jamaica flower drink (Mayol-Soto and Aragón-Vargas 2002), apfelschörle (Shirreffs, Aragón-Vargas, Keil, Love and Phillips 2007), and soft drinks (González Alonso, Heaps and Coyle 1992) resulted in a similar or lower fluid retention than water. None of these studies, however, have been as widely publicized as a 2009 report on the rehydration properties of beer which, to the best of our knowledge, has not yet been published in a peer-reviewed journal (Jiménez, Cervantes, Castillo, Romeo, and Marcos, 2009). Unfortunately, the popular media have extrapolated the study results to extremes most likely not intended by the researchers, and certainly not warranted by the study design: a claim that beer is the optimum beverage for rehydration.

The presence of alcohol in beer may induce an a priori negative judgment on its rehydration qualities. Alcohol intake does have a diuretic effect which follows a clear doseresponse relationship (Eggleton 1942, Murray 1932); this effect, however, may not be as relevant after dehydration from exercise in the heat and at lower alcohol concentrations. Shirreffs and Maughan (1997) compared beverages at 0, 1, 2, and 4\% of alcohol, and found that only at the higher concentration was there a small detrimental effect of alcohol on fluid retention. Hobson 
and Maughan (2010) gave $1 \mathrm{~L}$ of $4 \%$ beer or non-alcoholic beer in the morning to overnightfasted subjects, and found that the increased diuresis with alcohol was blunted when they were hypohydrated. In a review of the literature on hydration and physical activity, Casa, Clarkson and Roberts (2005) acknowledged that alcohol concentrations such as those in beer may not impair long term euhydration in athletes, but stated that when rapid and complete rehydration is the goal, beer should not be relied upon; they considered the evidence to be only preliminary. None of the aforementioned studies evaluated motor performance associated with exercise, dehydration, and alcohol intake. More recently, Irwin, Leveritt, Shum, and Desbrow, (2013) found that impairment of cognitive function due to alcohol ingestion is more pronounced after exercise and sweat loss without rehydration. Since regular beer is widely available and very palatable to many, it is an appealing candidate for post-exercise rehydration, but the alcohol effects on fluid retention and motor control need to be better understood and certainly warrant more experimental studies.

There is a dearth of data using beer with a more realistic alcohol concentration. Shirreffs and Maughan designed their study "to establish whether alcohol exerts a diuretic action when consumed by individuals in a water- and electrolyte depleted state induced by exercise in a warm, humid environment” (1997, p. 1152), not to evaluate the suitability of regular beer for postexercise rehydration. The alcohol concentrations used in their study were too low for that purpose, considering that a beer alcohol content of $4 \%$ or lower is the exception rather than the norm. Meanwhile, the effective dilution of beer in the 2009 study by Jiménez et al. (41\% beer, $59 \%$ water) would certainly lower the alcohol content of ingested fluid and its diuretic effect, a desirable result for rehydration purposes. It would also dilute all the electrolytes and any other solutes naturally present in beer; in this case, a potentially negative result for fluid retention. No clear statements can be made about beer itself under those conditions. 
What happens when humans drink regular, non-diluted beer after exercise-induced dehydration, as is often the case, is an open question. Is there a diuretic effect of alcohol, meaning an additional urine output beyond the effect of the ingested fluid volume? Does the presence of other nutrients in beer offset this effect? Is the resulting blood alcohol level high enough to impair motor control? The purpose of the present study was to assess the effects of post-exercise rehydration with beer on fluid retention, blood alcohol concentration, balance, and reaction time during three hours of follow up, and to compare them with non-alcoholic beer and water.

\section{Methods}

Participants: Eleven apparently healthy, physically active male college students, $24.4 \pm 3.7$ y.o., $75.4 \pm 10.2 \mathrm{~kg}$ of body mass $(\mathrm{BM})$ and $1.78 \pm 0.07 \mathrm{~m}$ tall (mean \pm S.D.), agreed to participate in the study, after passing an initial screening (legal drinking age; exercising a minimum of 1 hour, three times a week; used to drinking beer, but with no alcoholism problems as assessed by the questionnaire in Williams, 2006). The study was approved by the institutional Ethics and Science Committee prior to subject recruitment; each volunteer signed an informed consent after discussing the risks and benefits of his participation with the researchers. Each participant visited the laboratory the same day of the week, one week apart, one time for each beverage in a repeated-measures design; the order of tests was randomized.

\section{Procedures:}

Participants arrived in the laboratory in the morning after an overnight fast (at least 8 hours without food or drinks) and provided a plastic container with their first urine of the day. Urine samples were tested for urine specific gravity (USG) with a model URC - Ne, d 1.0001.050 manual refractometer $\left(A T A G O^{\circledR}\right.$, Tokyo, Japan), and discarded. After completely emptying 
their bladders, participants were weighed nude and dry to the nearest 10 grams on a calibrated scale (model DSB291, Romanas Ballar ${ }^{\circledR}$, San Jose, Costa Rica); this was their baseline body mass $\left(\mathrm{BM}_{\text {baseline }}\right)$. Blood alcohol content (BAC) was estimated from breath alcohol using an AlcoSensor FST ${ }^{\circledR}$ (Intoximeters, Inc., St. Louis, MO, USA) with a measurement range of 0.000 to $0.440 \mathrm{~g} / 210 \mathrm{~L}$ of breath, using the accepted conversion factor of $1: 2100$, resulting in a range of 0.00 to 4.4 grams of alcohol per liter of blood (g/L). Each volunteer was asked to exhale smoothly through a mouthpiece until the apparatus signaled sampling completion, and the corresponding result was recorded.

Participants ingested a standard 3356 kJ breakfast (23.9\% fat, 66.2\% carbohydrate, 12.0\% protein; $1112 \mathrm{mg}$ sodium and $250 \mathrm{~mL}$ fluid). After a 20 min rest, each participant completed a reaction time test and a balance test. The simple reaction time test required hitting a key as soon as possible upon presentation of the visual stimulus on a computer screen, ten consecutive times; an average score was obtained after discarding the best and the worst trials. False starts (pressing the key before a visual stimulus was presented) were identified by the software, assigned the worst score of the set, and included in the average, as a penalty. For the balance test, each participant was required to stand on the left foot, arms hanging at the sides, for $30 \mathrm{~s}$; data were collected on a Bertec $^{\mathrm{TM}}$ force platform (Model 6090-15, Columbus, OH, USA) at a sampling rate of $600 \mathrm{~Hz}$, and filtered with a fourth-order low-pass Butterworth filter with a cutoff frequency of $8 \mathrm{~Hz}$. Center of pressure velocity in the anteroposterior axis $\left(\mathrm{V}_{\mathrm{CoPx}}\right)$ and the lateral axis $\left(\mathrm{V}_{\mathrm{CoPy}}\right)$ were calculated according to the formula from Karlsson \& Frykberg (2000):

$$
\frac{f}{n-1} \sum_{i=1}^{n-1} \sqrt{(\operatorname{CoP}(i+1)-\operatorname{CoP}(i))^{2}}
$$

To complete preparation for dehydration, participants emptied their bladders again; the urine sample was weighed to the nearest gram on an OHAUS ${ }^{\circledR}$ CS-2000 food scale (OHAUS, 
Parsippany, NJ, USA), and the equivalent volume was recorded assuming $1 \mathrm{~g}$ is equivalent to 1mL. Another nude and dry body mass was obtained $\left(\mathrm{BM}_{\mathrm{pre}}\right)$, and BAC was measured.

Dehydration was induced by exercising in an environmental chamber at $31.7 \pm 1.6^{\circ} \mathrm{C}$ dry bulb and $55.0 \pm 8.3 \%$ relative humidity. Each participant pedalled on a stationary cycle at 70 $85 \%$ of maximum heart rate, $\left(\mathrm{HR}_{\max }=207-[0.7 *\right.$ age], Tanaka, Monahan and Seals 2001); heart rate was monitored using a Polar ${ }^{\circledR}$ S120 or a Polar ${ }^{\circledR}$ FT40 (Polar Electro Oy, Kempere, Finland). Each subject was weighed nude and dry every 20 minutes during a 5 minute rest; exercise was terminated when they approached the target dehydration equivalent to 2\%BM. Upon completion of exercise participants took a cold shower, emptied their bladders in a plastic container for USG and volume measures, registered a nude and dry body weight, and repeated the reaction time and balance tests.

Rehydration consisted of drinking a volume equivalent to $100 \%$ of lost weight, divided into four equal aliquots, one every 15 minutes. On one occasion they ingested Cristal ${ }^{\circledR}$ bottled water (WATER), on another they drank a regular beer (Imperial ${ }^{\circledR}$ ) with 4.6\% alcohol (BEER), and the other day a non-alcoholic beer (Kaiser ${ }^{\circledR}$ ) with $0.5 \%$ alcohol (NAB) (see Table 1), according to the randomly assigned order for each person. All beverages were manufactured by Florida Ice \& Farm Co., San Jose, Costa Rica.

Table 1. Beverage composition*

\begin{tabular}{|c|c|c|c|}
\hline \multirow[t]{2}{*}{ Ingredient } & \multicolumn{3}{|c|}{ Beverage } \\
\hline & WATER & BEER & NAB \\
\hline Alcohol (ABV) (\%) & 0 & 4.6 & 0.5 \\
\hline Carbohydrate (g) & 0 & 3.4 & 3.4 \\
\hline Protein (g) & 0 & 0.2 & 0.3 \\
\hline Sodium $\left(\mathrm{mEq} * \mathrm{~L}^{-1}\right)$ & 0.30 & 2.61 & 3.91 \\
\hline Potassium $\left(\mathrm{mEq} * \mathrm{~L}^{-1}\right)$ & 0.12 & 2.30 & 3.07 \\
\hline Calcium $\left(\mathrm{mEq} * \mathrm{~L}^{-1}\right)$ & 0.30 & 1.25 & 2.00 \\
\hline Magnesium $\left(\mathrm{mEq} * \mathrm{~L}^{-1}\right)$ & 0.42 & 0.97 & 1.16 \\
\hline Energy (kJ) & 0 & 193 & 62 \\
\hline
\end{tabular}

*Note: alcohol is reported as mL of alcohol per $100 \mathrm{~mL}$ of product; carbohydrate, protein and energy are presented per $100 \mathrm{~g}$ of product. 
Whence the one-hour rehydration was completed, participants emptied their bladders and completed another round of BAC, reaction time, and balance tests. This was repeated every 30 minutes for a total of three hours. At the end of monitoring they were weighed nude and dry one final time. Net fluid balance (NFB) was calculated in milliliters by subtracting initial body mass in kilograms from body mass at each of four time points: baseline, after dehydration, postrehydration, and at the end of monitoring. An equivalence of $1 \mathrm{~g}$ to $1 \mathrm{~mL}$ was used.

Statistical analysis: A descriptive analysis was carried out on all variables, including skewness and kurtosis, to check for normality. One-way, repeated measures analyses of variance (ANOVA) were performed for the baseline measurements (BM, USG, BAC, $\mathrm{V}_{\mathrm{CoPx}}, \mathrm{V}_{\mathrm{CoPy}}$, and reaction time) prior to each of the three conditions. Exercise intensity and duration, dehydration, and ingested volume were also compared with one-way, repeated measures ANOVAs.

Urine output was analyzed in two different ways. First, with a one-way, repeated measures ANOVA to compare the total urine output and the fraction of ingested fluid that was retained, for the three conditions. Then, a two-way repeated-measures ANOVA (condition X time) for partial and accumulated urine outputs. Two-way, repeated measures ANOVAs were also applied to NFB, BAC, reaction time, and balance $\left(\mathrm{V}_{\mathrm{CoPx}}\right.$, and $\left.\mathrm{V}_{\mathrm{CoPy}}\right)$. Sphericity was tested for every repeated-measures ANOVA with Mauchly's test, and the appropriate degrees of freedom adjustment was made, when pertinent. When significant main effects were found (p < 0.05), post-hoc analysis was performed with a Bonferroni adjustment. When the interaction was significant $(\mathrm{p}<0.05)$, a manual post-hoc analysis of simple effects for time and for condition, with a Tukey adjustment, was performed according to the method of Keppel (1973). All the other analyses were performed with SPSS v. 21. 


\section{Results}

Participants showed the same baseline hydration, body mass, BAC, balance, and reaction time before all conditions (Table 2). Blood alcohol level was confirmed at zero for all the participants and all the conditions. Overall exercise heart rate was $153 \pm 12$ beats*min ${ }^{-1}$ and exercise time $67 \pm 12$ minutes; dehydration during this time was $2.12 \pm 0.20 \% \mathrm{BM}$, with no significant differences among conditions. Accordingly, participants ingested statistically equal volumes of each fluid (1.60 $\pm 0.22 \mathrm{~L})$ (Table 3). The average intake of ethanol during rehydration was $60.1 \pm 6.5 \mathrm{~g}$ for BEER and $6.4 \pm 1.0 \mathrm{~g}$ for NAB.

Table 2. Baseline values. Mean \pm S.D.

\begin{tabular}{|c|c|c|c|c|c|}
\hline \multirow{2}{*}{\multicolumn{2}{|c|}{ Variable }} & \multicolumn{3}{|c|}{ Condition } & \multirow{2}{*}{ p-value } \\
\hline & & WATER & BEER & NAB & \\
\hline \multicolumn{2}{|l|}{ BM (kg) } & $75.50 \pm 10.62$ & $75.40 \pm 10.42$ & $75.45 \pm 10.54$ & 0.756 \\
\hline \multicolumn{2}{|l|}{ USG } & $1.017 \pm 0.008$ & $1.019 \pm 0.009$ & $1.015 \pm 0.004$ & 0.356 \\
\hline \multicolumn{2}{|l|}{ BAC (g/L) } & 0.00 & 0.00 & 0.00 & 1.000 \\
\hline \multicolumn{2}{|c|}{ Reaction time (s) } & $0.285 \pm 0.034$ & $0.289 \pm 0.026$ & $0.283 \pm 0.037$ & 0.766 \\
\hline \multirow{2}{*}{$\begin{array}{l}\text { Balance } \\
\left(\mathrm{m}^{*} \mathrm{~s}^{-1}\right)\end{array}$} & Vel COPX & $0.025 \pm 0.00 €$ & $0.025 \pm 0.005$ & $0.026 \pm 0.009$ & 0.849 \\
\hline & Vel COPy & $0.036 \pm 0.006$ & $0.035 \pm 0.008$ & $0.036 \pm 0.008$ & 0.928 \\
\hline
\end{tabular}

Table 3. Reference values for dehydration and rehydration. Mean \pm S.D.

\begin{tabular}{|c|c|c|c|c|}
\hline \multirow[t]{2}{*}{ Variable } & \multicolumn{3}{|c|}{ Condition } & \multirow{2}{*}{ p-value } \\
\hline & WATER & BEER & NAB & \\
\hline Exercise heart rate (beats $* \min ^{-1}$ ) & $150 \pm 15$ & $154 \pm 12$ & $153 \pm 11$ & 0.817 \\
\hline Exercise time (min) & $64.4 \pm 7.8$ & $66.4 \pm 10.7$ & $70.0 \pm 16.6$ & 0.369 \\
\hline Dehydration (BM\%) & $2.01 \pm 0.20$ & $2.20 \pm 0.26$ & $2.15 \pm 0.24$ & 0.056 \\
\hline Ingested volume $(\mathrm{mL}$ & $1517 \pm 197$ & $1655 \pm 167$ & $1619 \pm 260$ & 0.074 \\
\hline Ethanol intake $(\mathrm{g})^{*}$ & $0.0 \pm 0.0$ & $60.1 \pm 6.5$ & $6.4 \pm 1.0$ & $3.3 \times 10^{-11}$ \\
\hline
\end{tabular}

*Note: ethanol intake in grams was calculated by multiplying fluid intake in $\mathrm{mL}$, times the reported percent alcohol by volume ( $4.6 \%$ for BEER, $0.5 \%$ for $\mathrm{NAB})$, and by alcohol density $(0.789 \mathrm{~g} / \mathrm{mL})$.

Fluid retention was lower for BEER than the other two beverages. Total urine output was significantly greater for BEER $(1218 \pm 279)$ than both NAB $(745 \pm 313, \mathrm{p}=0.007)$ and WATER (774 $\pm 304, p=0.043$ ) (Figure 1). The fraction of ingested fluid that was retained was smaller for BEER $(26.3 \pm 14.7 \%)$ than NAB $(53.3 \pm 19.1 \%, \mathrm{p}=0.002)$ and WATER $(48.1 \pm 21.4 \%, \mathrm{p}=$ 
0.022). Partial urine volumes showed a significant interaction between condition and time $(\mathrm{F}=$ 3.196, $\mathrm{p}=0.0002$ ), and both the main effects were significant as well. BEER had a significantly higher urine output at 30 minutes (301.4 mL [243.8, 358.9]) (mean [95\%CI]) and 60 minutes (295.5 [255.9, 335.2]) relative to post-exercise $(133.8[69.1,198.5])(\mathrm{p}<0.05)$. Both NAB and WATER showed lower urine outputs towards the end of monitoring, compared with postexercise (Figure 2). Partial urine output was higher for BEER than WATER already at the end of rehydration $($ time $=0 \mathrm{~min})(208.4 \mathrm{~mL}[146.2,270.6]$ and $95.0 \mathrm{~mL}[58.9,131.1]$, respectively, $\mathrm{p}<$ 0.05). This difference persisted at the 30- and 60-min time points, but disappeared after that. BEER urine output was only different from NAB at the 60-minute mark (295.5 mL [255.9, 335.2] and 135.0 mL [74.5, 195.5], respectively, $\mathrm{p}<0.05)$.

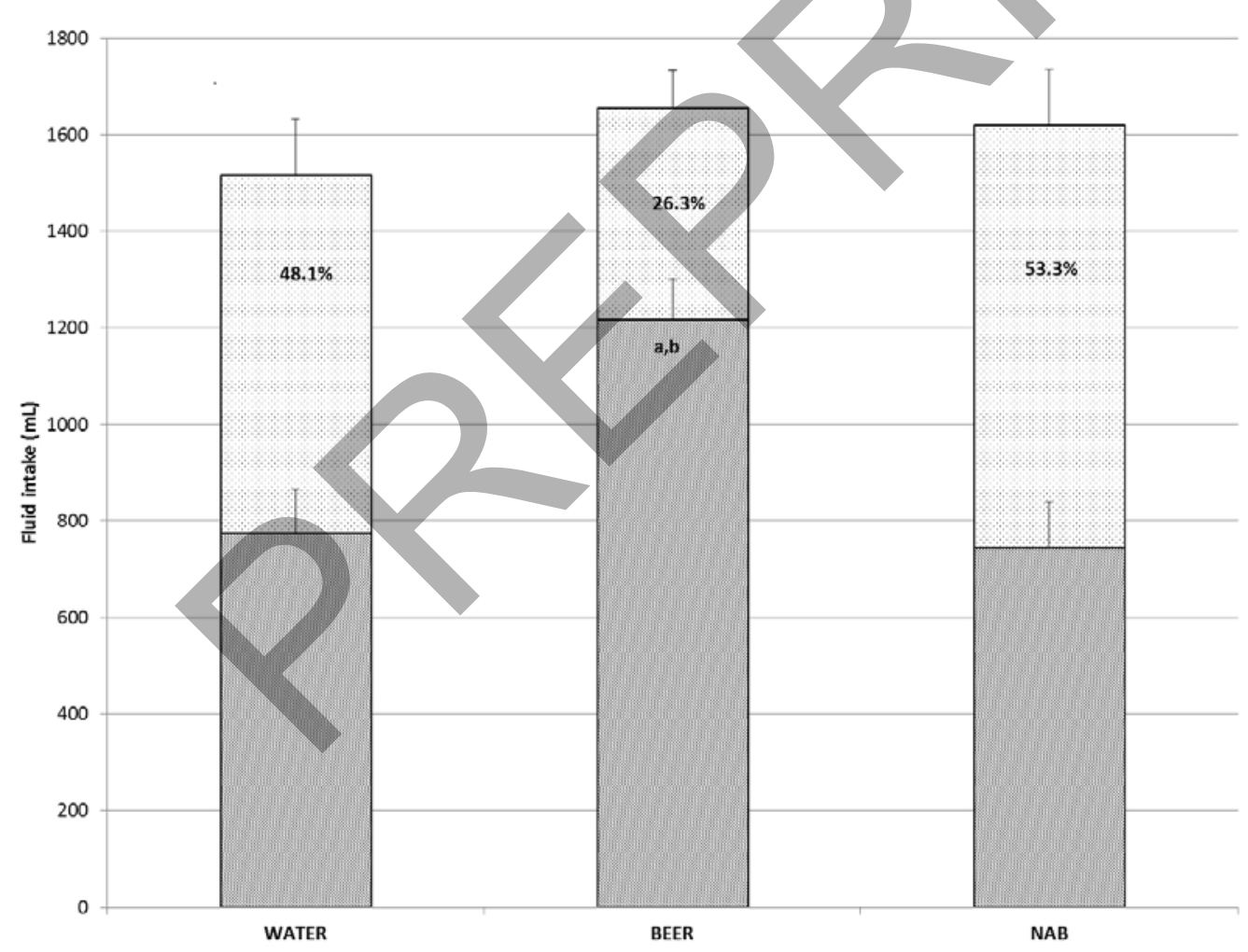

Figure 1. Fluid intake and total urine output.

Columns are mean values plus standard error of the mean. $F=8.63, p=0.002$. Lower portion of each column represents urine output, upper portion is the volume that was retained.

(a) Urine volume different from WATER, $p=0.043$. (b) Urine volume different from $N A B, p=0.007$ 


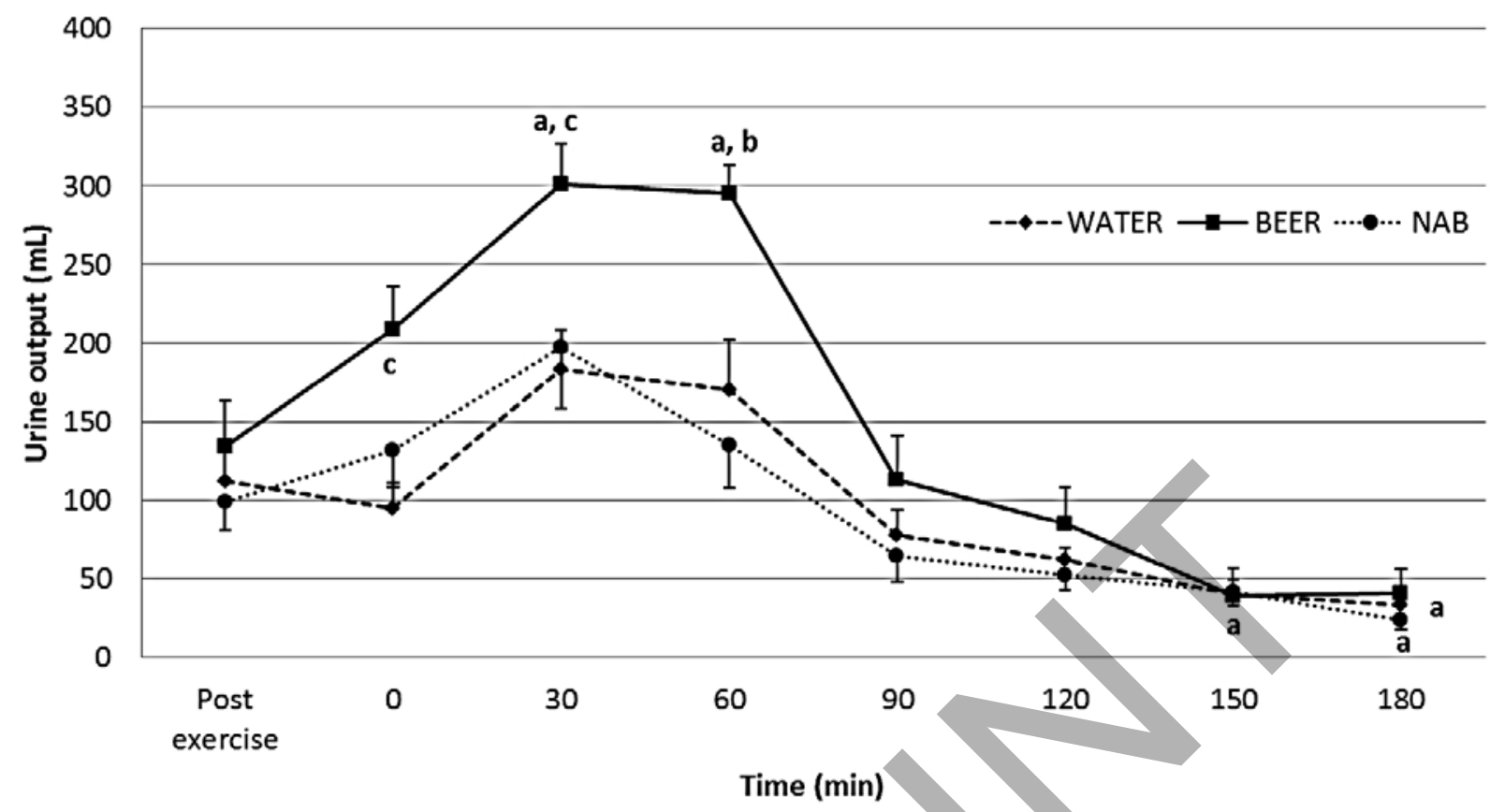

Figure 2. Partial urine output.

Points are mean values; bars represent standard errors of measurement. Interaction $F=3.20, p=$ 0.0002. Condition main effect $F=8.63, p=0.002$. Time main effect $F=33.49, p=0.00018$.

(a) Different from post-exercise $(p<0.05)$. (b) Different from NAB and WATER $(p<0.05)$ (c) Different from WATER $(p<0.05)$.

Cumulative urine output showed a significant interaction $(\mathrm{F}=6.88, \mathrm{p}=0.025)$, as well as significant main effects for condition $(F=9.74, \mathrm{p}=0.001)$ and time $\left(\mathrm{F}=148.88, \mathrm{p}=2.5 \times 10^{-7}\right)$. All the time points were different among them $(\mathrm{p}<0.05)$. There was no difference between NAB and WATER, but BEER (208.4 mL [146.2, 270.6]) was higher than WATER (95.0 mL [58.9, 131.1]) at 0 minutes and thereafter. $\operatorname{BEER}(805.3 \mathrm{~mL}$ [689.8, 920.7]) was also higher than NAB (463.8 $\mathrm{mL}[295.2,632.4])$ at 60 minutes and thereafter.

As shown in Figure 3, net fluid balance was lower after rehydrating with beer. There was a significant interaction between condition and time $(F=9.31, p=0.012)$. There was a significant main effect for condition $(\mathrm{F}=10.49, \mathrm{p}=0.001)$ and also for time $\left(\mathrm{F}=312.41, \mathrm{p}=7.2 \times 10^{-9}\right)$. As 
a main effect, all the time points were different among them $(\mathrm{p}<0.005)$. However, net fluid balance at the end of monitoring with BEER was not different $(167.3 \mathrm{~mL}$ higher, $\mathrm{p}>0.05)$ from the dehydrated time point in the same condition. NFB after rehydration was less than initial for BEER (-258 mL, p < 0.05), but not for NAB or WATER (-133 and -109 mL, respectively). After dehydrating with exercise, NFB was higher for WATER than BEER (138 mL higher, p < 0.05). At the end of the three hours of monitoring, BEER had a lower NFB than WATER and NAB (494 and $-568 \mathrm{~mL}$ respectively, $\mathrm{p}<0.05$ ). There were no other differences among conditions at the other time points.

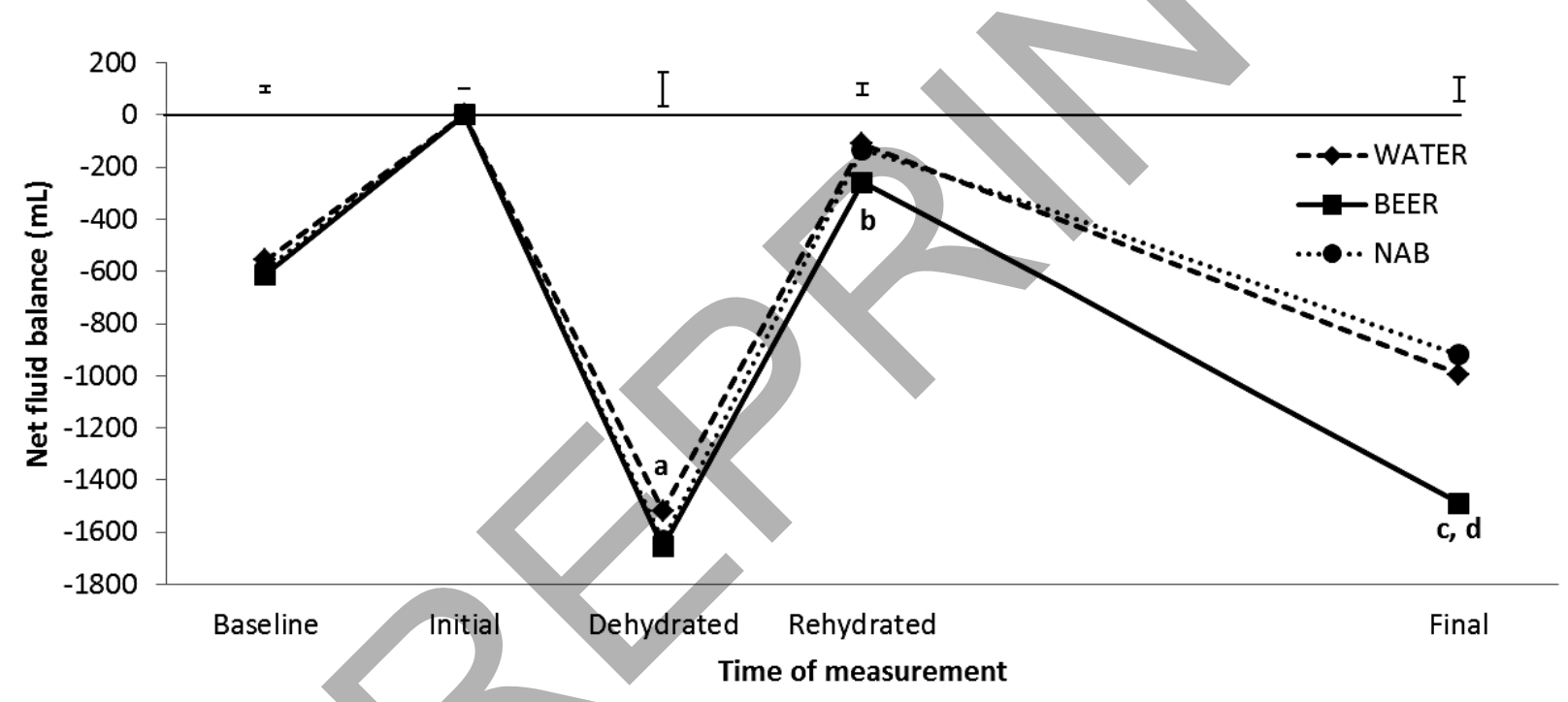

Figure 3. Net fluid balance.

Points are mean values; upper bars represent group standard errors of measurement. Interaction $F=$ 9.31, $p=0.012$. Condition main effect $F=10.49, p=0.001$. Time main effect $F=312.41, p=7.2 \times 10^{-9}$. Simple effects: (a) Different from BEER $(p<0.05)$ (b) Different from initial (zero) $(p<0.05)$ (c) Different from NAB and WATER $(p<0.05)$. (d) NOT different from Dehydrated ( $p>0.05)$. Baseline is presented for reference only; food and drink were ingested after baseline and before the initial body weight.

Blood alcohol concentration (BAC) was zero at all time points for both WATER and NAB. BEER showed a marked increase from post-exercise to the end of consumption (time 0 min), reaching $0.857 \mathrm{~g} / \mathrm{L}[0.752,0.963]$ (mean [95\% C.I.]); it decreased slowly afterwards to $0.486 \mathrm{~g} / \mathrm{L}$ [0.427, 0.545] (Figure 4). Minimum and maximum individual BAC at the end of 
consumption were 0.57 and $1.21 \mathrm{~g} / \mathrm{L}$, respectively, while at the end of the three hours they were 0.36 and $0.70 \mathrm{~g} / \mathrm{L}$, respectively (Figure 5).

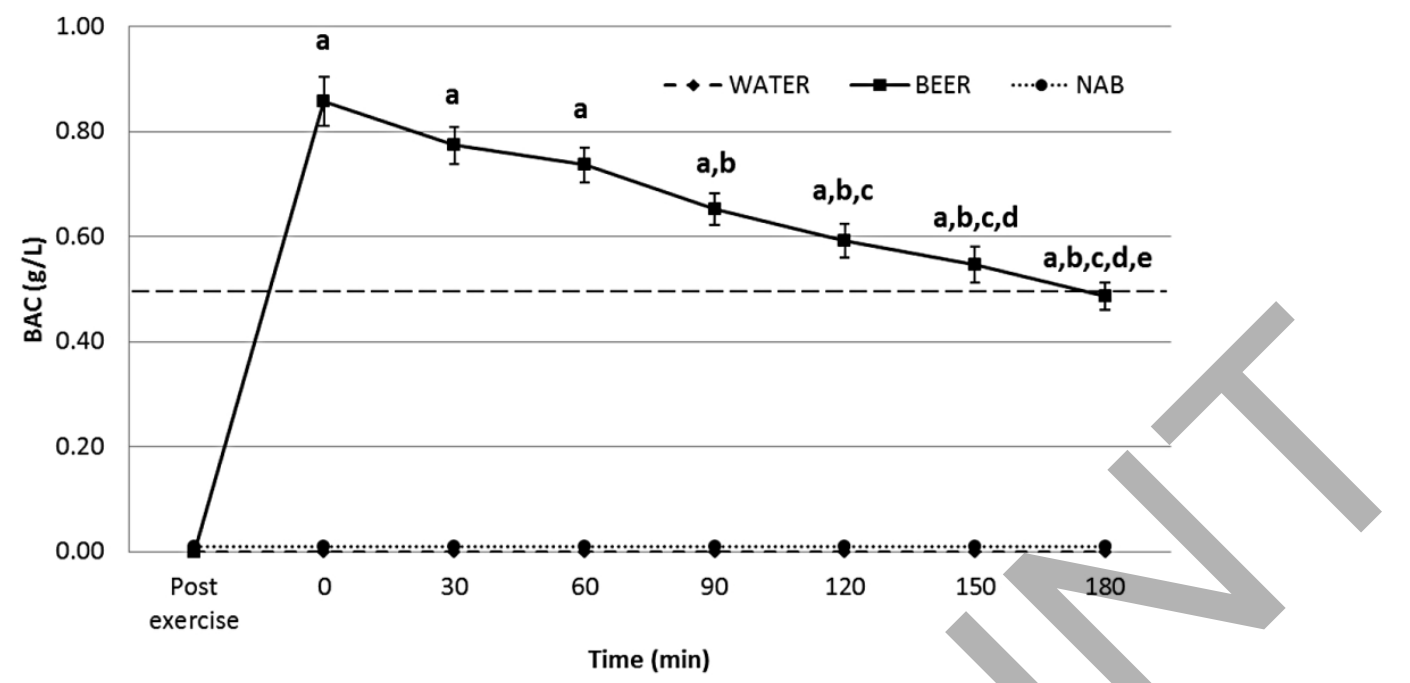

Figure 4. Blood alcohol content.

Points are mean values; bars represent standard error of the mean. Interaction $F=214.1, p=4.4 \times 10^{-8}$. Condition main effect $F=442.3, p=1.3 \times 10^{-9}$. Time main effect $F=214.1, p=4.4 \times 10^{-8}$.

(a) Different from post-exercise $(p<0.05)$. (b) Different from $0 \mathrm{~min}(p<0.05)$ (c) Different from $30 \mathrm{~min}$ $(p<0.05)$. (d) Different from $60 \mathrm{~min}(p<0.05)$. (e) Different from $90 \mathrm{~min}(p<0.05)$.

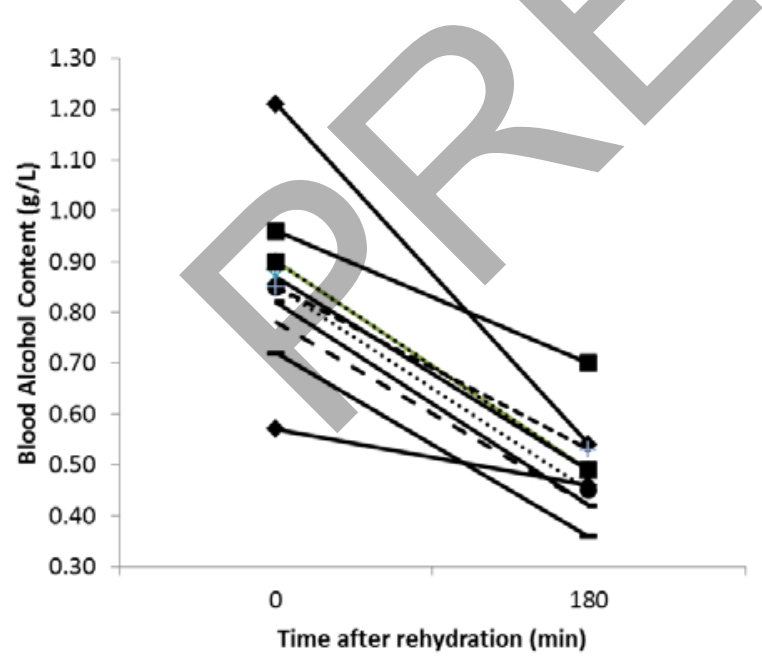

Figure 5. Individual blood alcohol content.

Points are individual values. The slopes of the lines connecting the two time points for each individual illustrate the different rates of ethanol metabolization. 
Reaction time was longer for BEER $(0.314 \pm 0.039$ s, mean \pm S.D. $)$ than NAB $(0.294 \pm$ 0.034s, $\mathrm{p}=0.009)$, but no different from WATER $(0.293 \pm 0.049 \mathrm{~s}, \mathrm{p}=0.077)$ (Figure 6). There was no significant interaction between condition and time $(\mathrm{F}=0.96, \mathrm{p}=0.351)$, and no main effect of time $(F=1.35, p=0.273)$ on $R T$.

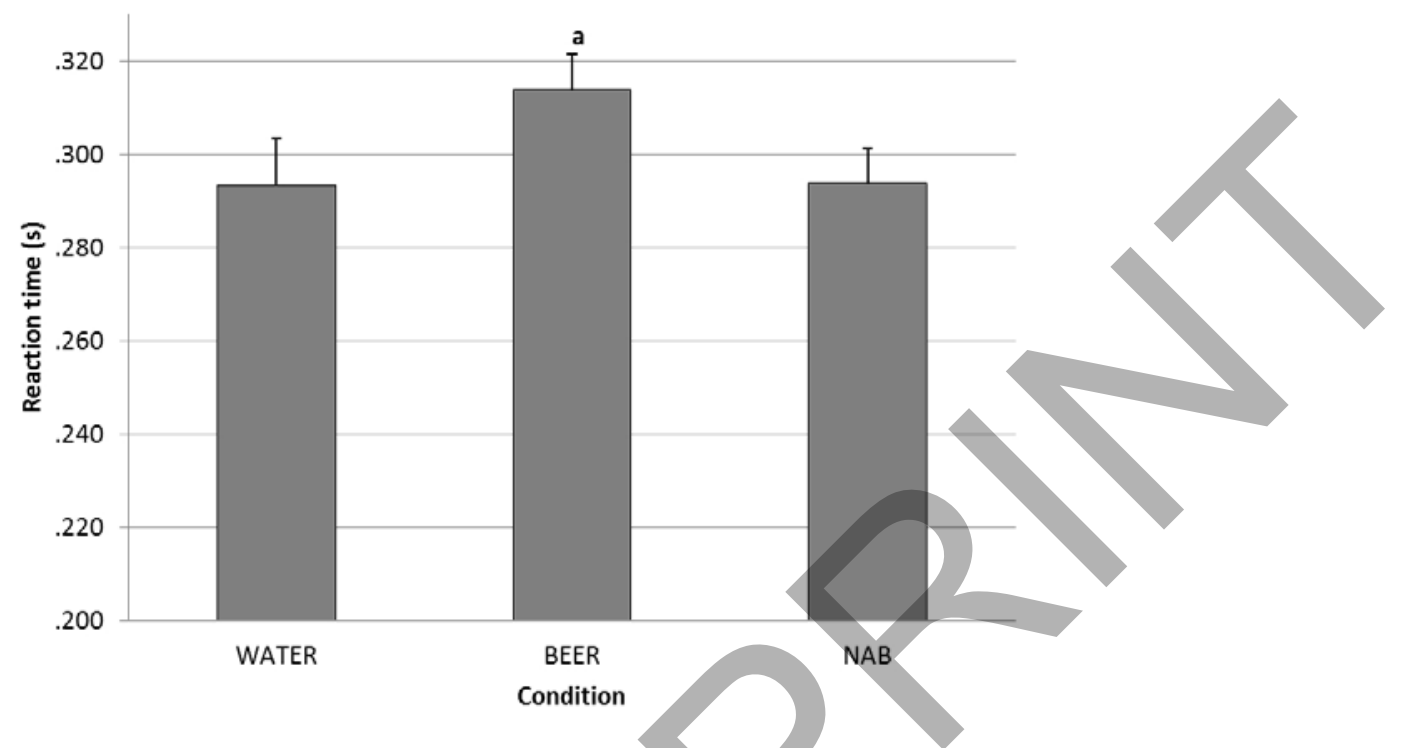

Figure 6. Reaction time.

Columns are mean values plus standard error of measurement. $F=7.342, p=0.004$. (a) Different from $N A B(p=0.009)$

Balance results are presented in Figures 7 and $8 . \mathrm{V}_{\mathrm{CoPx}}$ showed a significant interaction between condition and time $(\mathrm{F}=2.481, \mathrm{p}=0.004)$. The condition main effect was significant: BEER $0.0284 \pm 0.0020 \mathrm{~m} * \mathrm{~s}^{-1} ;$ NAB $0.0233 \pm 0.0010 \mathrm{~m} * \mathrm{~s}^{-1}$; WATER $0.0238 \pm 0.0010 \mathrm{~m} * \mathrm{~s}^{-1}$ (mean \pm S.E.M.) $(\mathrm{F}=7.296, \mathrm{p}=0.022)$, while there was no main effect for time $(\mathrm{F}=0.951, \mathrm{p}=$ 0.353). Balance was significantly impaired for BEER from the end of rehydration up to 90 minutes of follow up, compared with both WATER and NAB ( $<<0.05$, see Figure 7).

$\mathrm{V}_{\text {CoPy }}$ showed a non-significant interaction between condition and time $(\mathrm{F}=1.563, \mathrm{p}=$ 0.059), with no main effects for condition $(F=3.263, p=0.059)$ or time $(F=0.998, p=0.440)$. See Figure 8. 


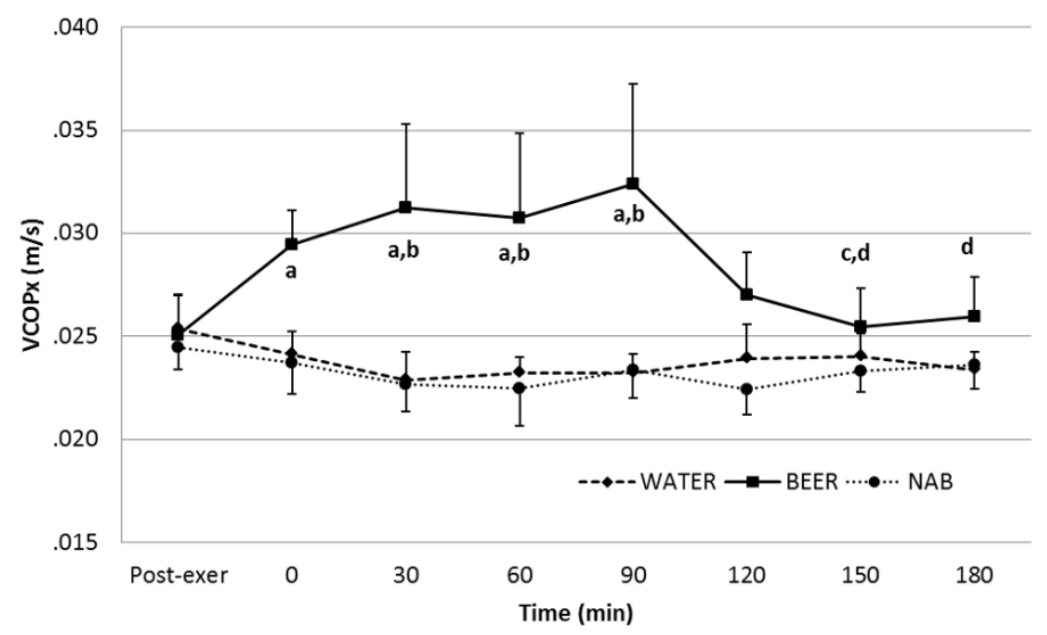

Figure 7. Anteroposterior balance $\left(V_{\mathrm{CoPx}}\right)$.

Points are mean values; bars represent standard errors of measurement. Interaction $F=2.481, p=0.004$. Condition main effect $F=7.296, p=0.022$. Time main effect $F=0.951, p=0.353$.

(a) Different from NAB and WATER $(p<0.05)$. (b) Different from post-exercise. (c) Different from $30 \mathrm{~min}$ $(p<0.05)$. (d) Different from $90 \min (p<0.05)$.

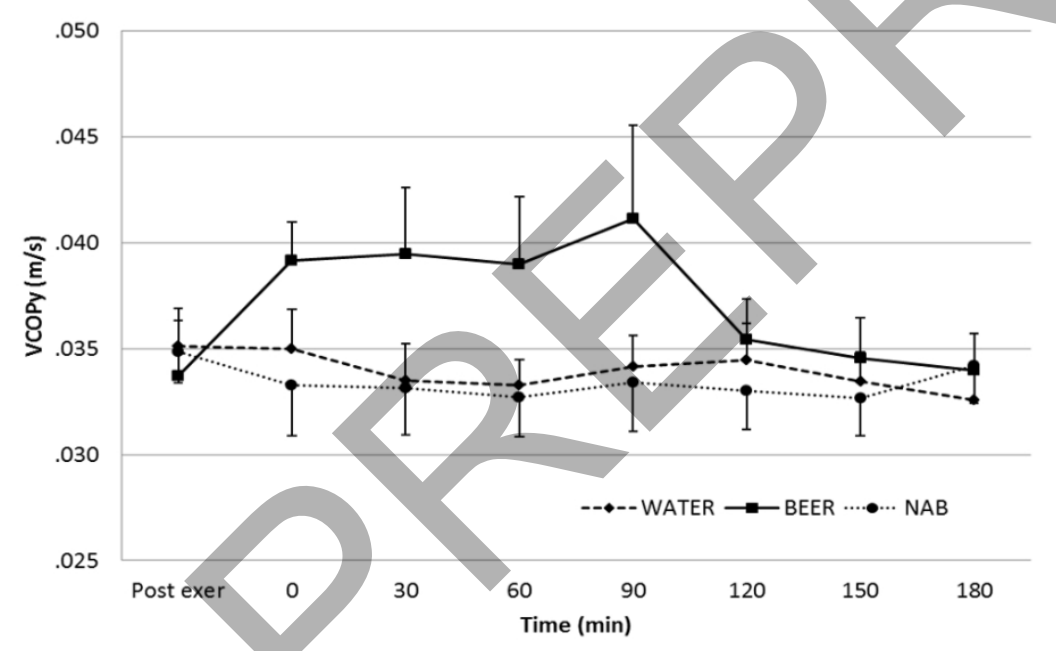

Figure 8. Lateral balance $\left(V_{\mathrm{CoPy}}\right)$.

Points are mean values; bars represent standard errors of measurement. Interaction $F=1.563, p$ $=0.059$. Condition main effect $F=3.263, p=0.059$. Time main effect $F=0.998, p=0.440$.

\section{Discussion}

The major finding of the present study was that regular beer is not a good choice as a post-exercise rehydration drink. Rehydration with beer resulted in a lower fluid retention than 
rehydration with water or non-alcoholic beer. Motor performance was also impaired. For all the differences shown when BEER was compared with NAB, the results can be attributed to the presence of alcohol in the former, the major difference in beverage composition between them.

In our study, the fraction of the ingested fluid that was retained amounted to a mere $26.3 \pm$ 14.7\% with a $4.6 \%$ alcohol drink after three hours of monitoring, while the study by Shirreffs \& Maughan (1997) obtained $40.7 \pm 16.7 \%$ with the $4 \%$ alcohol drink, even after 6 hours of monitoring. Even though our drinks had a lower potassium concentration $\left(2.3\right.$ and $3.1 \mathrm{mEq} * \mathrm{~L}^{-1}$ for BEER and NAB, respectively, vs. $10 \mathrm{mEq} * \mathrm{~L}^{-1}$ in their study), our sodium was slightly higher (2.6 and $3.9 \mathrm{mEq} * \mathrm{~L}^{-1}$ vs. $2 \mathrm{mEq} * \mathrm{~L}^{-1}$ ). The total amount of ethanol ingested in our study was less (60.1 \pm 6.5 g compared with $68.0 \pm 3.9 \mathrm{~g})$ and resulted in a lower peak BAC $(0.857 \mathrm{~g} / \mathrm{L}$ compared with $0.967 \mathrm{~g} / \mathrm{L})$. Since the fraction of ingested fluid that was retained was more similar between the two studies with NAB, we speculate that our subjects may not have been as habituated to consuming alcohol. Another possibility is that the higher alcohol concentration in our beer (4.6\%) had a greater impact on diuresis than the concentration in Shirreffs and Maughan’s study (4.0\%), but we are unable to explain this from the BAC measurements.

Shirreffs and Maughan (1997) found no significant differences in urine output or NFB between the $4 \%$ alcohol drink and the no alcohol beer. We found a significantly lower NFB for BEER than for the other two drinks after three hours of monitoring. Cumulative urine output was already greater for BEER than NAB 30 minutes after completing fluid intake. It is possible that their sample size (6 subjects) was too small to detect the differences; their values show the same tendency as ours. The study by Hobson and Maughan (2010) did not find a significant difference in urine output between $4.0 \%$ alcohol beer and non-alcoholic beer when their 12 subjects were hypohydrated, but they ingested only $31.6 \mathrm{~g}$ of ethanol (irrespective of body mass) $14 \mathrm{~h}$ after exercise-induced dehydration, compared to $\approx 60 \mathrm{~g}$ in the present study. When their subjects were 
allowed to achieve euhydration prior to alcohol intake, diuresis was higher. That was also the case if alcohol was analyzed as a main effect, including both the euhydrated and hypohydrated conditions. Therefore, both Shirreffs and Maughan (1997) and Hobson and Maughan (2010) point in the same direction as the present results.

Our results disagree with the prevailing interpretation of the study by Jiménez et al. (2009). The study design used by that group, a comparison between ad libitum rehydration with water (1644 $\pm 620 \mathrm{~mL}$ ), and rehydrating with $660 \mathrm{~mL}$ of beer plus ad libitum intake of water (960 $\pm 587 \mathrm{~mL}$ ) over two hours, is not appropriate in order to conclude that beer is as effective as water, even though their total urine output was similar $(223 \pm 245$ and $281 \pm 374 \mathrm{~mL}$, respectively; urine output was only measured during the two-hour rehydration period). The present study used only beer, only water, or only non-alcoholic beer, to replace $100 \%$ of fluid lost during exercise $(1597 \pm 216 \mathrm{~mL}$ of fluid); urine output over three hours was greater with BEER, a statistically significant difference but also a practically relevant difference of about $450 \mathrm{~mL}$.

The standard recommendation for a good post-exercise rehydration involves drinking a volume equivalent to $150 \%$ of weight loss, to compensate obligatory urine losses (Sawka et al. 2007). However, in order to avoid giving too much alcohol to our participants, we decided to use a lower volume (100\%). This resulted in a very poor net fluid balance at the end of monitoring. It also resulted in NFB never being positive: it did not reach zero at the very end of rehydration because of high urine output (Figure 3). Nevertheless, we were able to identify clear disadvantages for BEER compared to the other two beverages (see figures 1, 2, and 3). After rehydration with BEER, end-of-monitoring NFB was not statistically higher than NFB immediately post-exercise, before fluid intake. It is not possible, from the present results, to estimate if euhydration could be achieved and maintained by drinking a $4.6 \%$ alcohol beer alone after dehydrating to 2\%BM, and if so, how much beer would be necessary. 
Motor performance was impaired after ingesting BEER: reaction time was slower for the BEER condition than for NAB, and it did not change over the time of monitoring; one measure of balance $\left(\mathrm{V}_{\mathrm{CoPx}}\right)$ showed an impairment for the BEER condition from 30 to 90 minutes after ingestion, while the other $\left(\mathrm{V}_{\mathrm{CoPy}}\right)$ did not reach statistical significance, even though it followed the same pattern over time. A study by Irwin et al. (2013) showed an impairment in cognitive skills when exercise-dehydrated subjects ingested alcohol, and showed that this negative effect on a choice reaction time task was attenuated if the subjects were more fully rehydrated. Another way to interpret their data is that reaction time impairment was actually greater when alcohol was combined with exercise-induced dehydration. In that study, the amount of alcohol ingested in vodka (after drinking water with $\mathrm{NaCl}$ ) was not reported, but their subjects reached peak BAC values $\approx 0.72 \mathrm{~g} / \mathrm{L}$. Both the data from Irwin et al. (2013) and ours confirm what was already known about the deterioration of motor skills under the influence of alcohol in the absence of exercise, the basis for legal driving restrictions in most of the world. In addition, our data are, to the best of our knowledge, the first published for men who drank plain alcoholic beer to rehydrate after exercising in the heat.

In the present study, mean blood alcohol content was just below the legal limit for driving in many countries, i.e., $0.50 \mathrm{~g} / \mathrm{L}$, after three hours of monitoring. Individual BAC responses, however, were highly variable, despite ingesting an amount of ethanol proportional to body mass under highly standardized conditions: at the end of consumption, minimum and maximum BAC were 0.57 and $1.21 \mathrm{~g} / \mathrm{L}$, respectively, while at the end of the three hours they were 0.36 and 0.70 g/L, respectively, and not for the same subjects (Figure 5). This confirms in exercise-dehydrated subjects a well-known fact: individuals metabolize blood alcohol at different rates (Jones, 2007).

The present study showed a remarkable similarity between the diuresis responses to nonalcoholic beer and water. Because of its composition and the absence of alcohol, NAB could have 
shown greater fluid retention than water, but it did not. In fact, the sodium and potassium concentrations in NAB were too low (3.9 and $3.1 \mathrm{mEq} * \mathrm{~L}^{-1}$ ) to make any difference (Maughan \& Shirreffs 1996, Palacios et al. 2008, Shirrefs \& Maughan 1998), a detail already pointed out by Shirreffs and Maughan in their report on alcoholic beverages (1997).

In conclusion, under the conditions of this study (2\%BM dehydration from exercising in the heat, replacing $100 \%$ of sweat loss in one hour), regular beer with $4.6 \%$ alcohol was not a good choice for post-exercise rehydration: urine output was considerably higher than when water or non-alcoholic beer were used, and both reaction time and balance were impaired. In addition, non-alcoholic beer offered no rehydration advantages over plain water. In the light of these results, the popular recommendation of beer for post-exercise rehydration is not warranted.

\section{Acknowledgments}

Supported by project UCR-VI-245-B0-315, and Educalcohol Costa Rica.

\section{References}

Aragón-Vargas, L.F., Moncada-Jiménez, J., Hernández-Elizondo, J., Barrenechea, A., and Monge-Alvarado, M. 2009. Evaluation of pre-game hydration status, heat stress, and fluid balance during professional soccer competition in the heat, Eur. J. Sport Sci. 9(5): 269276. DOI: $10.1080 / 17461390902829242$.

Casa, D., Clarkson, P., and Roberts, W. 2005). American College of Sports Medicine Roundtable on Hydration and Physical Activity: Consensus Statements. Current Sports Medicine Reports 4:115-127. Available from http://www.acsm.org/docs/publications /Roundtable\%20on\%20Hydration\%20and\%20Physical\%20Activity.pdf [accessed 11 December 2013].

Eggleton, M. 1942. The diuretic action of alcohol in man. J. Physiol. 101: 172-191. 
González-Alonso, J., Heaps, C., and Coyle, E. 1992. Rehydration after exercise with common beverages and water. Int. J. Sports Med. 13: 399-406.

Hobson, R. M. and Maughan, R. J. 2010. Hydration Status and the Diuretic Action of a Small Dose of Alcohol. Alcohol Alcoholism 45(4): 366-373.

Irwin, C., Leveritt, M., Shum, D., and Desbrow, B. 2013. The effects of dehydration, moderate alcohol consumption, and rehydration on cognitive functions. Alcohol 47(3): 203-13.

Ismail, I., Singh, R., and Sirisinghe, R.G. 2007. Rehydration with sodium-enriched coconut water after exercise-induced dehydration. Southeast Asian J. Trop. Med. Public Health 38(4): 769-785.

Jeukendrup, A., Currell, K., Clarke, J., Cole, J., and Blannin, A. 2009. Effect of beverage glucose and sodium content on fluid delivery. Nutr. Metab. (London) 6(9): 1-7.

Jiménez, D., Cervantes, M., Castillo, M., Romeo, J., and Marcos, A. 2009. [Idoneidad de la cerveza en la recuperación del metabolismo de los deportistas]. Cerveza y Salud 17. Available from http://www.cervezaysalud.es/pdf biblioteca/17.Idoneidad_cerveza_recuperacion_metabol ismo_deportistas_08_82.pdf [accessed 11 December 2013].

Jones, A. 2007. Body Mass Index and Blood Alcohol Calculations. J. Anal. Toxicol. 31: 177-178.

Kalman, D. S., Feldman, S., Krieger, D. R., and Bloomer, R. J. 2012. Comparison of coconut water and a carbohydrate-electrolyte sport drink on measures of hydration and physical performance in exercise-trained men. J. Int. Soc. Sports Nutr. 9(1): 1.

Karlsson, A., and Frykberg, G. 2000. Correlations between force plate measures for assessment of balance. Clin. Biomech. 15: 365-369.

Keppel, G. 1973. Design and analysis, a researcher’s handbook. Prentice Hall, Inc., Englewood Cliffs, N.J. 
Maughan, R., and Shirreffs, S. 1996. Recovery from prolonged exercise: Restoration of water and electrolyte balance. J. Sports Sci. 15: 297-303.

Mayol-Soto M.L., and Aragón-Vargas LF. 2002. [Rehidratación post-ejercicio con diferentes tipos de bebidas: agua pura, bebida deportiva, y agua de jamaica]. Revista De Ciencias Del Ejercicio y La Salud, 2(1): 41-54.

Murray, M. M. 1932. The diuretic action of alcohol and its relation to pituitrin. J. Physiol. 76(3): 379-386.

Palacios, N., Bonafonte, L., Manonelles, P., Manuz, B., and Villegas, J. 2008. [Consenso sobre bebidas para el deportista. Composición y pautas de reposición de líquidos]. Archivos de Medicina del Deporte 25(126): 245-258.

Pérez-Idárraga, A., and Aragón-Vargas, L.F. 2011. [Rehidratación post-ejercicio con agua de coco: ¿igual o más efectiva que una bebida deportiva?] MH Salud 8(1): 1-16.

Saat, M., Singh, R., Sirisinghe, R. G., and Nawawi, M. 2002. Rehydration after exercise with fresh young coconut water, carbohydrate-electrolyte beverage and plain water. J. Physiol. Anthropol. Appl. Human Sci. 21(2): 93-104.

Sawka, M. N., Burke, L. M., Eichner, E. R., Maughan, R. J., Montain, S. J., and Stachenfeld, N. S. 2007. American College of Sports Medicine position stand. Exercise and fluid replacement. Med. Sci. Sports Exerc. 39(2): 377-90.

Shirreffs, S., and Maughan, R. 1997. Restoration of fluid balance after exercise-induced dehydration: effects of alcohol consumption. J. Appl. Physiol. 83(4): 1152-1158.

Shirreffs, S., and Maughan, R. 1998. Volume repletion following exercise induced volume depletion in man: replacement of water and sodium losses. Am. J. Physiol. 274: 868-875. 
Shirreffs, S.M., Taylor, A.J., Leiper, J.B., and Maughan R.J.. 1996. Post-exercise rehydration in man: effects of volume consumed and sodium content of ingested fluids. Med. Sci. Sports Exerc. 28(10): 1260-1271.

Shirreffs, S. M., Aragon-Vargas, L. F., Keil, M., Love, T. D., and Phillips, S. 2007. Rehydration after exercise in the heat: a comparison of 4 commonly used drinks. Int. J. Sport Nutr. Exerc. Metab. 17(3): 244-58.

Shirreffs, S. M., Watson, P., and Maughan, R. J. 2007. Milk as an effective post-exercise rehydration drink. Br. J. Nutr. 98(1): 173-80.

Tanaka, H., Monahan, K., and Seals, D. 2001. Age-Predicted Maximal Heart Rate Revisited. J. Am. Coll. Cardiol. 37(1): 153-156.

Williams, M. (2006). [Nutrición para la salud, la actividad física y el deporte]. McGraw-Hill, México, D.F.

Wong, S. H., and Chen, Y. 2011. Effect of a carbohydrate-electrolyte beverage, lemon tea, or water on rehydration during short-term recovery from exercise. Int. J. Sport Nutr. Exerc. Metab. 21(4): 300-310. 